\title{
An inventory of the South African fitness industry
}

\author{
Catherine E Draper ${ }^{1}(\mathrm{MA}, \mathrm{PhD})$ \\ LiesI Grobler ${ }^{1}(\mathrm{PhD})$ \\ Georgina A Kilian² (MBA) \\ Lisa K Micklesfield ${ }^{1}(\mathrm{PhD})$ \\ Estelle V Lambert ${ }^{1}$ (MS, PhD) \\ Timothy D Noakes ${ }^{1}$ (MB ChB, MD, DSc, FACSM) \\ ${ }^{1}$ UCT/MRC Research Unit for Exercise Science and Sports Medicine, University of Cape Town \\ ${ }^{2}$ Sports Science Institute of South Africa, Cape Town
}

\begin{abstract}
Objective. The aim of this study was to create an inventory of fitness facilities in South Africa, their location, equipment and services offered, and the demographics, education and training of the staff working in these facilities.

Design. A total of 750 facilities were identified, and descriptive data were gathered from 442 facilities (59\%) with the use of a questionnaire administered telephonically and via the website of the Sports Science Institute of South Africa.
\end{abstract}

Setting. The study was initiated by the Sports Science Institute, and the results were presented at the 4th Annual Discovery Vitality Fitness Convention on 4 May 2006.

Results. Results show that the industry comprises mainly independent facilities (68\%). All types of facilities were found to be located mostly within urban areas, and reported providing services to just less than $2 \%$ of the South African population. Facilities offer a wide range of equipment and services to their members. Of the fitness-related staff at facilities, the majority were reported to be young (18 - 25 years, $55 \%$ of male, and $49 \%$ of female staff), and in terms of racial proportions most staff were white (males $40 \%$ of total staff and females $33 \%$ of total staff).

\section{CORRESPONDENCE:}

\section{Cathi Draper}

UCT/MRC Research Unit for Exercise Science and Sports Medicine

Sports Science Institute of South Africa

Boundary Road

Newlands

7700

Tel: (021) 6504567

E-mail: cdraper@sports.uct.ac.za
Less than a quarter of fitness-related staff hold university qualifications, and just over $80 \%$ of instructors hold qualifications aligned with the National Qualifications Framework. The importance of education and training of staff was emphasised by respondents.

Conclusions. This report highlights the widespread value of assessing the fitness industry, particularly within the context of the rise of chronic diseases in South Africa and government initiatives to promote healthy lifestyles.

\section{Introduction}

At present the South African fitness industry has not been well researched, and no comprehensive inventory exists that lists all facilities comprising this industry. Among many of the key players within the South African fitness industry, there seems to be a general awareness of the facilities and service providers in the larger multipurpose gyms and health clubs, but there is limited information available concerning smaller, single-purpose clubs, community-based organisations and self-employed fitness instructors.

The International Health, Racquet and Sportsclub Association (IHRSA) works to produce data on the fitness industry worldwide, mainly through their annual Global Report - State of the Health Club Industry ${ }^{3}$ and their European Market Report. ${ }^{5}$ Based in the USA, IHRSA also conducts an Industry Data Survey of the Health and Fitness Club Industry ${ }^{4}$ within the USA. Data in this survey include, among other measures, club member demographics, club membership growth, club facilities, club growth, benchmarks by club type and size, and club prices. IHRSA has links with fitness associations in other countries and helps those organisations to produce similar reports.

Currently South Africa does not have a single entity representing the fitness industry, and to date, no equivalent of the IHRSA industry surveys and report. This should be seen 
as important as the fitness industry represents a significant vehicle for social and economic development in South Africa, as employer, through the provision of jobs, and as consumer, through improving health and thereby potentially reducing the burden of disease. ${ }^{13-15}$ Ideally, as a country and economy undergoing transition, South Africa requires its own industry standards and benchmarks, to meet specific needs and underserved communities. In addition, those in the South African fitness industry should have an accurate picture of the industry as a whole in order to respond appropriately to the health and fitness needs of the people they are aiming to serve. Shortfalls in the industry must also be identified against these needs.

Within the South African context, there are a number of governmental drives promoting physical activity, such as the 'Vuka SA - Move for your health' initiative, Sport and Recreation's Mass Participation programme, the Youth Fitness and Wellness Charter, and the Health-Promoting Schools Initiative. These initiatives are a response to the rise in chronic diseases, both nationally and internationally, and the identification of the lack of physical activity as a risk factor for many of these diseases. ${ }^{6-8,11-15}$ This makes it essential for South Africans to engage in physical activity and take responsibility for their health, and the fitness industry undoubtedly has a major role to play in promoting this. It is not only important to assess what role this industry is playing in getting and keeping South Africans active, but it is also important to evaluate the extent to which the needs of all South Africans are being, or can be, met by the industry.

Therefore, this study aimed to answer the following research questions:

- What fitness facilities exist in South Africa?

-Where are these facilities located within South Africa?

-What equipment, facilities and services are offered at those facilities?

-What are the demographics of the staff employed in those facilities?

- What is the level of education and training of fitness-related staff currently employed in those facilities?

\section{Methodology}

\section{Sample selection}

For the purposes of this research, the fitness industry is defined to include all multipurpose fitness centres, single-purpose fitness centres, exercise programmes within community halls or centres, hospital fitness centres, corporate fitness centres, hotel or resort fitness centres, college and university fitness centres, military fitness centres, aerobics, dance, katabox, pilates, yoga and cycling studios. Personal trainers and instructors without a fixed place of practice or employment were included, but all sporting clubs, facilities and organisations, whether recreational or competitive, were not included. Participants and facilities were sourced via the telephone di- rectory (white and yellow pages), the Internet and through personal networking and informers. Ethical approval for this study was obtained from the Research Ethics Committee at the University of Cape Town.

\section{Data-gathering methods}

A questionnaire was developed and pilot tested among key informants in the fitness industry who were known to the research team, and appropriate changes were made. Individuals who own or manage the specific facilities were contacted, and the questionnaire was then emailed to contacts for whom email addresses could be sourced. A number of questionnaires were administered telephonically by the research team, and respondents were also able to fill in the questionnaire via the Sports Science Institute of South Africa (SSISA) website. Other contacts were referred to a call centre which administered the questionnaire on behalf of the research team.

A total of 750 facilities were sourced and 'geocoded' at suburb level. For this process of 'geocoding', the geographical co-ordinates of the suburb in which each facility is located are plotted geographically, and results of this process are represented in Fig. 1. Fifty-nine per cent of the 750 facilities $(N=442)$ responded to the questionnaire. The remaining 308 facilities either did not complete the questionnaire or they could not be contacted because of incorrect contact details.

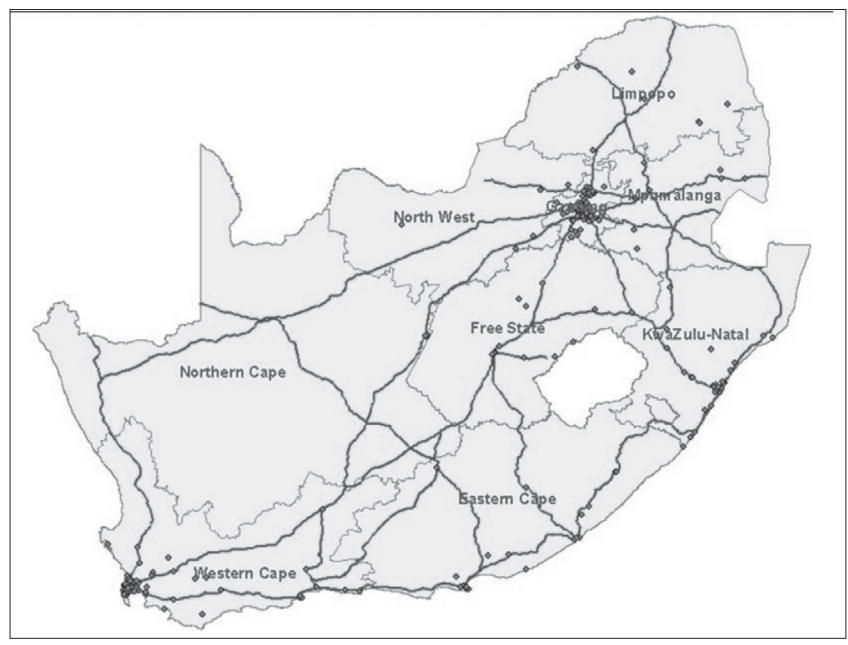

Fig. 1. Geocoding of 750 fitness facilities currently operating in South Africa.

\section{Results}

\section{Nature of facilities}

Respondents were asked to choose from a list of options that best described the fitness facility in which they work, and from these descriptions, facilities were then divided into four categories: (i) independent facilities (68\%), which included independent multipurpose fitness centres, single-purpose fit- 
ness centres, and group exercise studios for disciplines such as pilates, yoga and cycling; (ii) informal facilities (14\%), which included facilities that do not have dedicated exercise space or equipment, such as running and walking groups, exercise programmes in a community centre/hall/church hall; (iii) specialist facilities (7\%), which included facilities that exist because of the environment in which they are placed, such as facilities at tertiary academic institutions, hotels and resorts, hospitals and in corporate settings; and (iv) gym chains $(11 \%)$, which included multipurpose fitness facilities with more than one club under the same name.

\section{Size of facilities}

The average square meterage per facility with dedicated exercise space was calculated to be $1154 \mathrm{~m}^{2}(N=226)$, ranging from $20 \mathrm{~m}^{2}$ to $50000 \mathrm{~m}^{2}$. The average number of members per square meter for this type of facility was 1.8. The accuracy of this figure is, however, dependent on the information provided by facilities, as many respondents were only able to estimate the number of members and only 226 facilities were able to give the square meterage of their facility. The total number of members in the 442 facilities that reported their membership came to 813012 , only $1.73 \%$ of the total South African population estimated for $2005 .^{9}$

\section{Location and distribution of facilities}

Of the 442 facilities that responded to the questionnaire, 270 were placed in a large city, with 149 in a small city or town, and only 23 in a rural area. Definitions of these types of areas were not stipulated in the questionnaire, so the accuracy of these figures relies completely on the respondents' perceptions of the area in which they are placed. Fig. 1

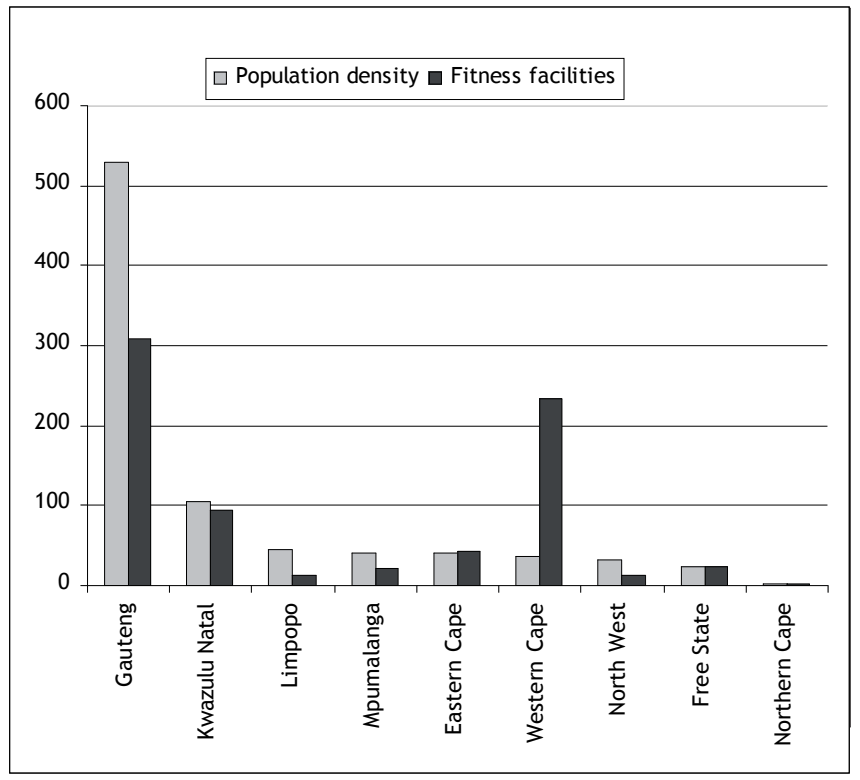

Fig. 2. Provincial distribution of South African fitness facilities and provincial population density in South Africa (persons per $\mathrm{km}^{2}$ ). shows the provincial distribution of the facilities in South Africa, and Fig. 2 presents this provincial distribution alongside the population density of each province in South Africa. ${ }^{2}$ It is clear from these figures that the distribution of facilities within South African provinces does seem generally to match the population density of these provinces, except for the Western Cape, which has the second highest number of fitness facilities (234) but a relatively low population density (36 persons per $\left.\mathrm{km}^{2}\right)$.

\section{Equipment, facilities and services offered}

Respondents were also asked to comment on the equipment, facilities, classes and programmes made available to the members of their facilities (Figs 3 and 4). Most facilities were able to provide exercise mats and free weights, and to a lesser degree cardiovascular equipment and mechanical resistance equipment (Fig. 3). The average number of group fitness sessions offered per week by facilities was 18. Eightyone per cent of facilities reported offering classes or programmes to the inactive or new exerciser, and Fig. 5 presents the various classes and programmes available to members.

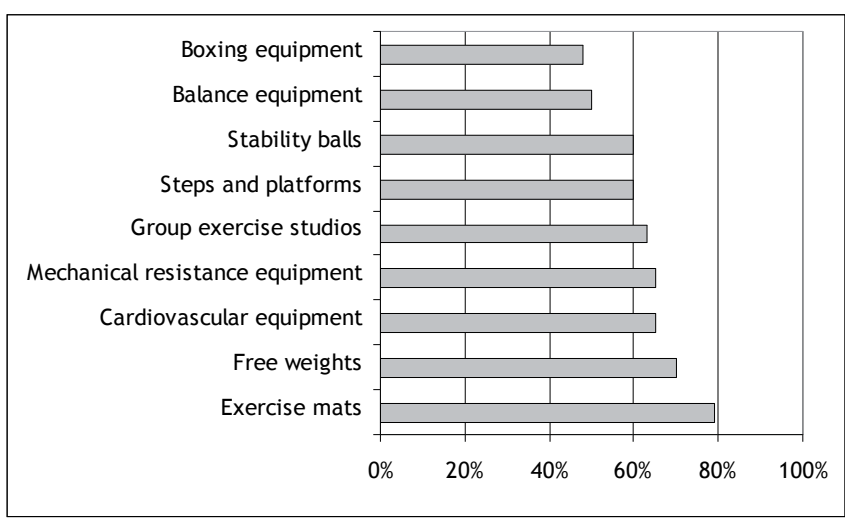

Fig. 3. Equipment available to members of fitness facilities.

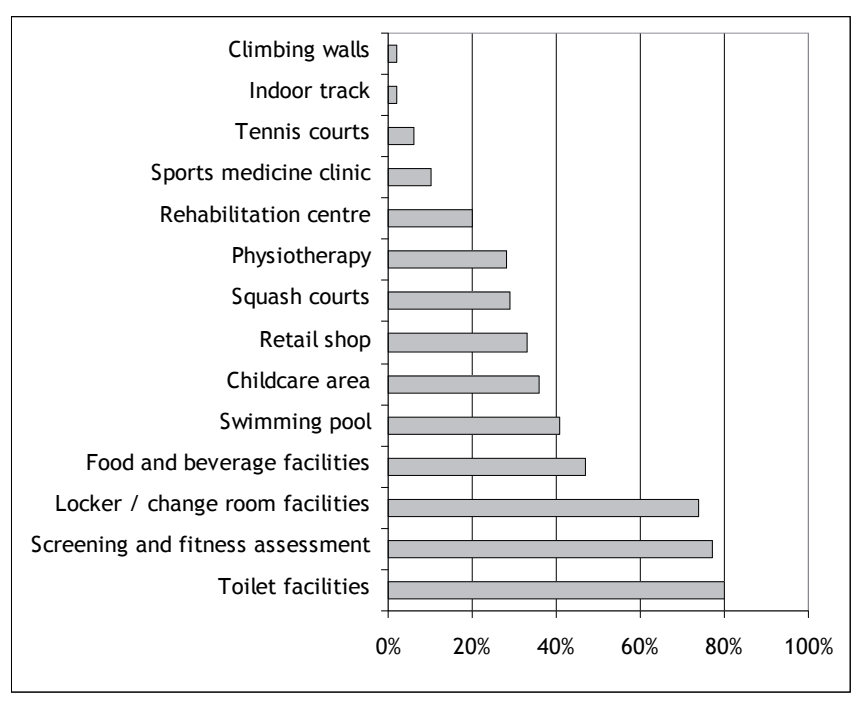

Fig. 4. Facilities offered to members of fitness facilities. 


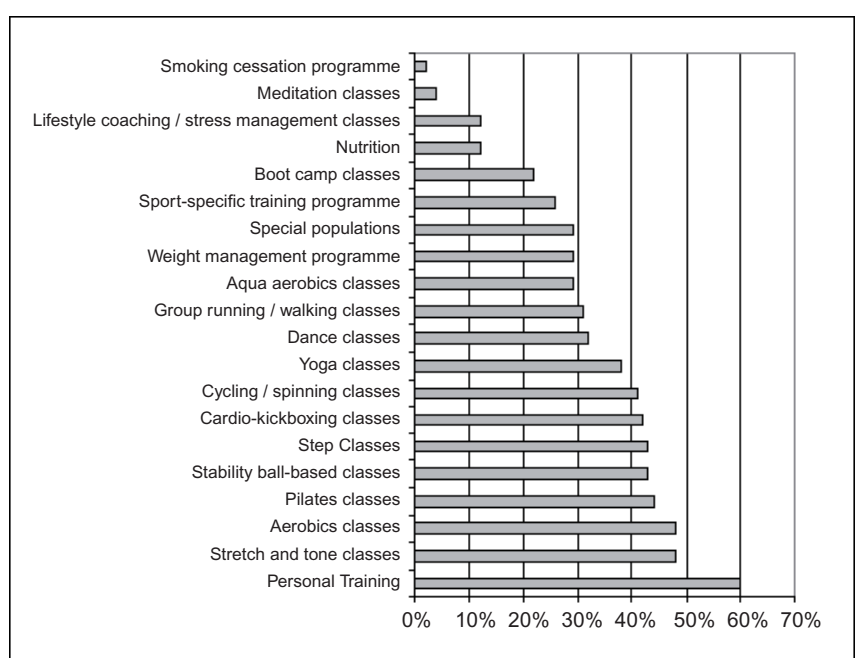

Fig. 5. Classes and programmes available to members of fitness facilities.

\section{Demographics of fitness-related staff}

Respondents were asked to provide information regarding the numbers and demographics of the fitness-related staff employed within the facility. Fitness-related staff were defined as all staff members within the facility who are involved in the health and fitness aspects of the facility. Examples given were biokineticists, personal trainers, fitness consultants, group fitness instructors and floor supervisors.

The average number of part-time fitness-related staff ranged from 2 in single-purpose fitness centres, to 7 in college/university fitness centres (specialist facilities). In multipurpose fitness centres, the average number of parttime fitness-related staff was 3 , and in group exercise studios the average number was 4 .

Regarding the ratio of personal and group fitness trainers in facilities sampled, multipurpose fitness centres had the highest ratio of members to trainers, with 872 members to each personal trainer, and 582 members to each group fitness trainer. Group exercise studios had a ratio of 236 members to each personal trainer, and 157 members to each group fitness trainer. Single-purpose fitness centres had a lower

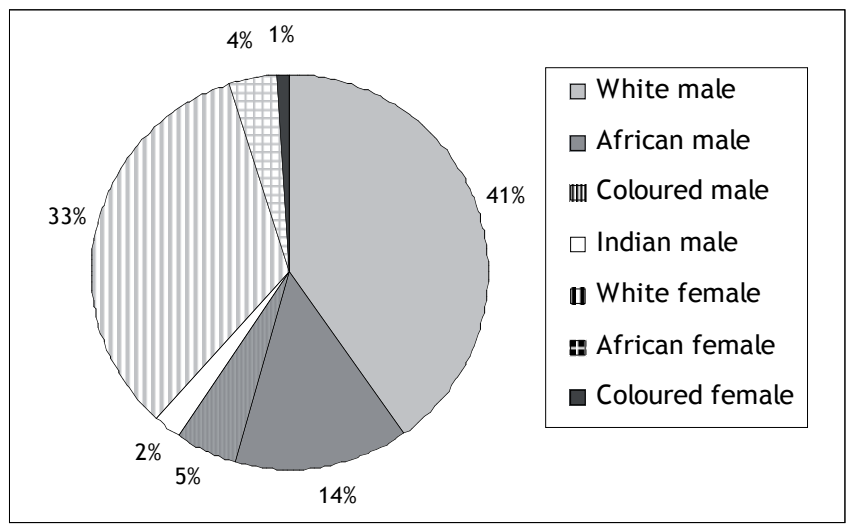

Fig. 6. Racial distribution of fitness-related staff.

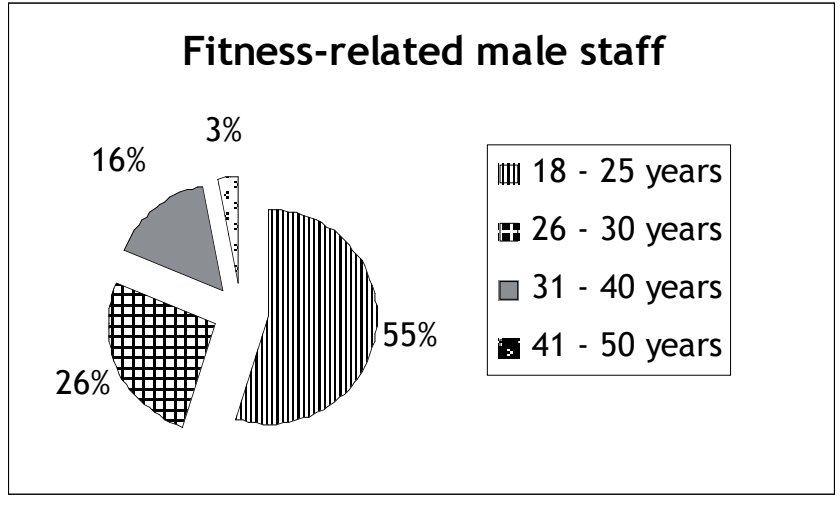

Fitness-related female staff

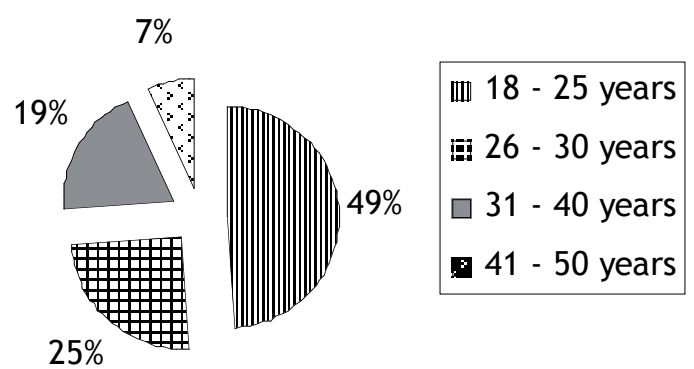

Fig. 7. Age distribution of fitness-related staff.

ratio of 127 members to each personal trainer, and a ratio of 159 members to each group fitness trainer.

Information regarding the demographics of fitness-related staff employed within the 442 facilities is presented in Figs 6 and 7 . The majority of fitness-related staff were young (18 - 25 years) white people. Sixty-one per cent of the staff were male. Less than $1 \%$ of the fitness-related staff were physically disabled.

\section{Qualifications of fitness-related staff}

Twenty-one per cent of the total fitness-related staff (both part-time and fulltime) hold university qualifications either in biokinetics $(11 \%)$ or exercise, sports or human movement science $(10 \%)$. Sixty-seven per cent of the staff were qualified in first aid and $73 \%$ were qualified in cardiopulmonary resuscitation (CPR). Fig. 8 presents the number of staff with diplomas aligned and not aligned with the National Qualifications Framework (NQF). Eighty-two per cent of the various types of instructors (aerobics, spinning, step class, pilates/ stretch and tone, yoga and pezzi ball instructors) hold NQFaligned diplomas.

All facilities falling under the category of gym chains, i.e. more than one club under the same name $(N=88)$, reported submitting a Tourism, Hospitality and Sport Education and Training Authority (THETA) skills levy plan and claimed to have benefited from THETA's skills levy process. Of the other facilities $(N=354)$, i.e. independent facilities, informal facilities and specialist facilities, only $89(25 \%)$ reported familiarity 




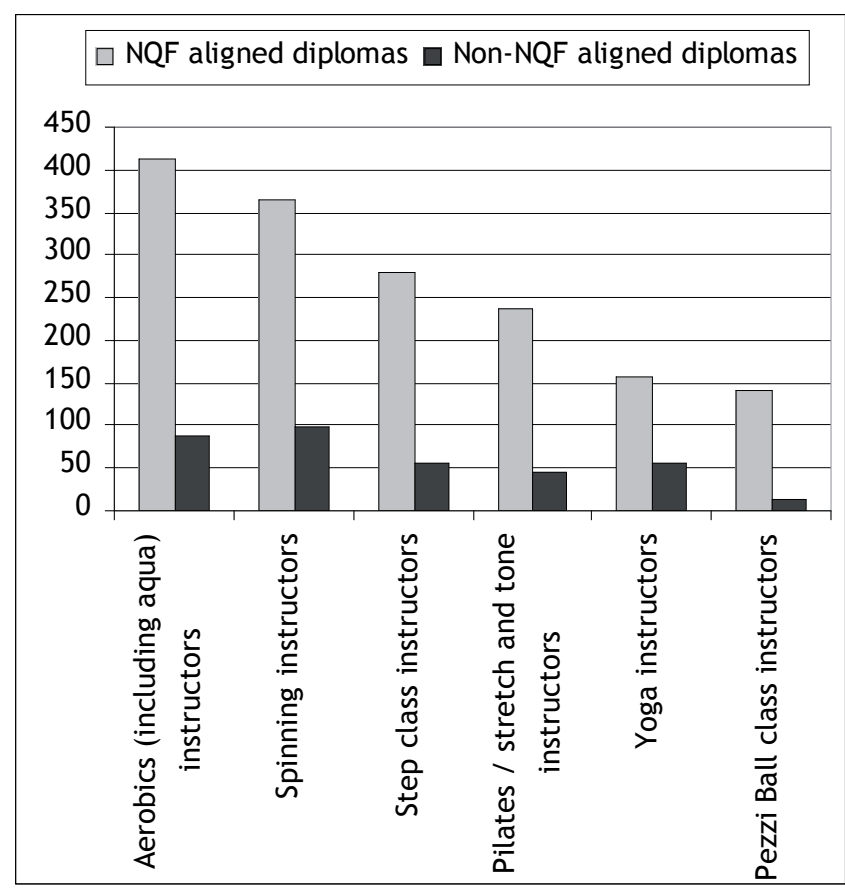

Fig. 8. Number of staff with NQF-aligned and non-aligned diploma qualifications.

with THETA's skills levy plan. Only $28(8 \%)$ of these facilities submit an annual skills levy plan to THETA, and only 18 (5\%) claimed to have benefited from THETA's skills levy process.

Similar discrepancies were evident between gym chain and other facilities (independent facilities, informal facilities and specialist facilities) in the area of continuing education. All gym chain facilities (100\%) stated continuing education as a requirement of fitness-related staff compared with $49 \%$ of other facilities. All gym chain facilities reported providing continuing education workshops to fitness-related staff, compared with $35 \%$ of other facilities, and the average number of continuing education workshops that staff should attend per year was 9 for gym chains as opposed to 4 in other facilities.

\section{Skills shortage in the fitness industry}

Respondents were asked an open-ended question about where they felt the greatest skills shortage lies in the fitness industry. A large portion of the responses referred to the education and training of staff, and the importance of qualification was emphasised. Some also stressed the importance of interpersonal (people) skills. Although not related to skills necessarily, some other issues were raised, including the importance of nutrition and the need for nutritionists, the need for facilities (size or type of facilities not specified), the public's lack of education about and awareness of physical activity and the need for healthy lifestyles, and the importance of regulation of the fitness industry.
The most valuable type of employee within the fitness industry

In another open-ended question, respondents were asked to identify the type of person, along with qualifications, who would be the most valuable employee in the fitness industry at present. In their responses there was a strong emphasis on the people skills and personality aspects of employees. Some of the personal qualities mentioned included enthusiasm, a passion for their work, and the ability to motivate and communicate with others. Personal qualities related more to the work ethic of employees, including commitment, reliability and dedication.

Within the responses to this second question the importance of qualification was once again emphasised, and some specific qualifications were mentioned as valuable in the industry. These included training in biokinetics, exercise, sports and human movement science, as well as personal training. In addition to this, training in areas such as sales, marketing, finance, business and general management were also thought to be important aspects of a valued employee of the health and fitness industry.

\section{Discussion}

From the results provided it is evident that independent facilities, which include multi- and single-purpose fitness centres, studios, etc., are most dominant in the industry, and that the fitness industry is broader than traditional gym and health clubs. The relatively small proportion of gym chains is not unique to South Africa, and in the USA, for example, gym chains comprise only $17 \%$ of the market. ${ }^{4}$

The statistics presented in this article should help to establish some useful standards for the South African fitness industry, but need to be considered in the context of international standards in order to establish how South Africa compares, particularly with regard to member numbers, average number of members per square meter, staff numbers and staff training. In the area of number of members as a percentage of the total population (penetration rate), South Africa has a percentage close to that of countries such as Mexico $(1.7 \%)$ and Chile $(1.9 \%)$, but is far behind developed countries such as Australia (8\%) and the USA (14\%). ${ }^{3}$

Comparing standards around staff numbers and training is, however, not as simple, as IHRSA's research tends to focus more on the economic aspects of staffing, and does not address staff qualifications and training. Information on staff in South African fitness facilities should, however, still be gathered, as standards on the ratios of staff to members may help to identify opportunities within the South African market. Further research would be required to assess the number of members who require or would choose the services of a personal trainer, as well as the number of members actually attending the various types of group fitness sessions. 
With regard to screening and fitness assessment offered to members, it is encouraging to note that a large percentage of facilities are offering this service (compared with $89 \%$ of USA facilities ${ }^{3}$ ) as the outcome of this type of assessment provides fitness-related staff with an indication of the level of members' fitness as well as the presence of potential health risks. However, it may be necessary to take a closer look at these assessments in order to determine whether facilities are complying with the minimum standards of screening as prescribed by the American College of Sports Medicine. ${ }^{1}$

Related to this is the number of fitness-related staff with university qualifications, and this links to the sports medicine and rehabilitation services being offered at facilities. If these numbers were to be increased it would mean that more facilities could offer such services, therefore enabling facilities to be better equipped to offer programmes to special populations, such as those suffering from a particular disease or condition.

\section{What is the value of assessing the state of the fitness industry?}

\section{From the health sector perspective}

The fitness industry has a major role to play within the government's initiatives encouraging physical activity and healthy lifestyles, and those driving government initiatives need upto-date information on the part the fitness industry is playing. They could use this project on an ongoing basis to assess the changes in physical activity in South Africans, e.g. what type of physical activity people are choosing to do, are gym memberships increasing, what are the trends in services and programmes offered, which aspects of the industry are growing? It would also be interesting to match these trends against South African and international media's health messages around physical activity and nutrition. Tracking these trends would also help to identify what types of facilities are sustainable over the long term.

Information on trends in the fitness industry can also help those driving government initiatives to tailor their recommendations, identify where their efforts should be placed and where support needs to be provided. In addition to this, the government's promotion of physical activity should help to increase the exercising population in South Africa, thereby creating opportunities within the fitness industry and identifying areas in which the government could provide or increase support. Ongoing research would therefore help to track the influence of this initiative on the growth of the industry, both in terms of the numbers of people exercising and the facilities and services that are being offered.

Although there is worldwide recognition among key players in the international fitness industry that this industry has a major role to play in promoting healthy lifestyles, not all markets have seen a measurable increase in their penetration rate. ${ }^{3}$ The USA, for example, has had a penetration rate of $14 \%$ for both 2003 and 2004, compared with 14.1\% in 2002. However, Brazil, with a slightly lower penetration rate than South Africa, has experienced an $8 \%$ growth in its fitness industry from 2003 to 2004 , and this growth is partly attributed to the public's heightened awareness of the need to lead healthy lifestyles. ${ }^{3}$ Similar growth in the South African fitness industry is therefore conceivable in light of the government initiatives currently promoting physical activity.

\section{From the industry perspective}

Research into the fitness industry would allow for the assessment of the shortfalls of the industry against the needs of members and communities, and through the identification of these shortfalls, opportunities would be created. One area of opportunity already mentioned is in the informal sector of the fitness industry, and this relates to the affordability of joining a fitness facility. The fitness industry needs to work on developing services that are suitable for certain areas where people are not able to afford gym fees but need to exercise.

Research into the fitness industry would also help to quantify the industry. By measuring its scope and size, greater confidence would be brought into the industry, and this in turn could result in increased funding opportunities. This would ultimately have a positive impact on the growth of the industry, and its credibility would be increased through the provision of formalised information.

Regarding developments within the South African fitness industry, a process has recently been initiated by key players in the industry to investigate the formation of a fitness industry body in South Africa, along the lines of IHRSA, in other parts of the world. However, IHRSA does not yet have affiliations to other countries in Africa, and South Africa would have to link with either the Asia-Pacific or the European market. Russia, classified by IHRSA as an emerging European market, has a penetration rate similar to South Africa's (1.8\%), and could possibly be compared with South Africa on account of the economic and political changes that have characterised the country's recent history. ${ }^{5}$ It has been argued that an increased interest in fitness in Russia has led to increased investor interest in the industry, ${ }^{3}$ boding well for the growth of the Russian fitness market, and highlighting the possibility of similar growth of fitness industries in other developing countries.

\section{From an education and training perspective}

The importance of both basic and continuing education has been highlighted, and these are fundamental to the future success of the fitness industry in South Africa. What has emerged confirms the need for continuing education and training for this industry, and ongoing research would help to monitor trends in education and training. Ongoing research 

into the fitness industry, which falls under the sub-sector of 'Sport, Recreation and Fitness' within THETA, is a vital means of providing data for the development of their strategic document, the Sector Skills Plan. ${ }^{10}$ Furthermore, having a better understanding of the industry would assist THETA in the decisions they make regarding education and training in this sub-sector, enabling them to improve standards of education and training, and ultimately increase the credibility of the fitness industry.

Regarding the certification of fitness-related staff, it is encouraging that the numbers of staff with NQF-aligned diplomas are greater than those with non-NQF-aligned diplomas, but the aim should be to ensure that all staff members have NQF-aligned qualifications in their field. Figures presented highlight the importance of the regulation of training within the industry, which is already being addressed by THETA. Compared with other countries worldwide, South Africa, through THETA and other education and training regulating structures, has made significant progress in the area of regulating the fitness industry, specifically in respect of the certification of fitness-related staff and accreditation of training sites. Based on the results around awareness of THETA's skills levy process, it is clear that more attention needs to be paid to educating fitness facilities about this process and the ways in which facilities can benefit from it.

Work still needs to be done in the area of continuing education in facilities other than gym chains, as well as in the area of the registration of fitness-related staff. It is quite likely that a formalised registration process for fitness-related staff could result in closer monitoring of the continued education of staff, such as is the case with health professionals and the continuing professional development points system. Overseeing the process of certification, accreditation and registration within the industry would need to be the responsibility of an industry body in South Africa.

\section{Gaps in this project and future research}

This project is the first of its kind undertaken in South Africa, so while progress has been made in setting up a database of fitness facilities, there are understandably gaps in this database, both in terms of the facilities included and the information gathered from facilities. Doing this type of research on an annual basis would help to refine the database and therefore better monitor the industry, create accurate and helpful industry benchmarks and provide useful information for the public and those with a vested interest in the fitness industry.

In terms of gaps in this project, facilities in community settings are not well represented as they proved difficult to contact, and the fact that there is no formal means of communication with them further highlights the need to include them in this type of research. These types of facilities need to be included so that a larger spectrum of socioeconomic status can be represented, and if such facilities do not exist, then this is an area to be addressed.
Other areas that could be investigated include membership agreements and membership fees at facilities in order to determine South African benchmarks. Such benchmarks would then help to gain insight into the type of commitment members are making and how affordable it is to join a fitness facility in South Africa. Membership retention and attrition rates, as well as member demographics, could also have been investigated, although the success of these types of investigations would rely on whether or not facilities have records on this information. Other financial aspects of the industry could also be explored, such as facility revenue and total revenue of the industry, industry revenue growth, wage rates for employees, and staffing costs.

From identifying the location of facilities, it is evident that the majority of facilities are in urban areas. There are clear gaps in rural and less urbanised areas, and future research would need to explore the reasons for these gaps so that they can be addressed where possible. It would be important to establish what types of facilities would be most suitable in these types of areas in terms of what would be successful and sustainable both from the business perspective as well as the health perspective. Unfortunately the present set of data does not give much guidance on this as there was no dominance of a particular type of facility in rural areas - a range of facilities were present in these areas.

There is also a lack of facilities in certain provinces, and further research needs to establish why this is the case have attempts been made in the past and have they been unsuccessful? In the future, a more detailed geocoding process could be used to obtain a better understanding of the areas in which facilities are placed, in terms of the distribution of socio-economic conditions and rural versus urban areas.

Further research would help to establish how staff and member demographics link to distribution of facilities around South Africa, and it is possible that the high number of white employees could be linked to the abundance of facilities in urban areas. From a human resources perspective, information on the staff within the industry helps to identify where there are gaps, and this information could start off the process of addressing these gaps. In a country promoting transformation, redress and equity, this should be seen as a priority. Ongoing research would also be able to track any changes in the percentages of certain racial groups that are not well represented and could also help to identify some of the reasons why this is the case.

\section{Conclusion}

Future research that covers the information mentioned above, along with the type of information already gathered in this project, would have widespread benefits. Ongoing research could no doubt contribute to the credibility and growth of South Africa's fitness industry, but also identify opportunities and areas in need of attention in the industry. South Africa faces the challenge of increasing the nation's physical activ- 

ity, and the fitness industry certainly needs to be part of rising to this challenge, particularly in the face of chronic diseases that could and do threaten the health of South Africans.

\section{Acknowledgements}

The research team would like to thank Bianca Meuer for her assistance in identifying facilities. Funding for this research was provided by THETA. These findings were presented at the 4th Annual Discovery Vitality Fitness Convention (4 - 6 May 2006, Vodaworld, Johannesburg) by Prof. Tim Noakes, Discovery Health Chair of Exercise and Sports Science, University of Cape Town.

\section{REFERENCES}

1. American College of Sports Medicine. ACSM's Guidelines for Exercise Testing and Prescription (7th ed). Philadelphia: Lippincott Williams \& Wilkins, 2006.

2. Health Systems Trust. Health statistics: population density (accessed 2006, May 22). Available from: http:www.hst.org.za/healthstats/20/data

3. International Health, Racquet and Sportsclub Association. IHRSA Global Report: State of the Health Club Industry 2005. Boston, MA: International Health, Racquet and Sportsclub Association, 2005.

4. International Health, Racquet and Sportsclub Association. Profiles of Success 2005: IHRSA's Industry Data Survey of the Health and Fitness Club Industry. Boston, MA: International Health, Racquet and Sportsclub Association, 2005

5. International Health, Racquet and Sportsclub Association. The IHRSA
2006 European Market Report: The Size and Scope of the Health Club Industry. Boston, MA: International Health, Racquet and Sportsclub Association, 2006.

6. Kruger HS, Puoane T, Senekal M, van der Merwe MT. Obesity in South Africa: challenges for government and health professionals. Public Health Nutr 2005; 8: 491-500.

7. Senekal M, Steyn NP, Nel JH. Factors associated with overweight/obesity in economically active South African populations. Ethn Dis 2003; 13: $109-16$

8. Sparling PB, Owen N, Lambert EV, Haskell WL. Promoting physical activity: the new imperative for public health. Health Educ Res 2000; 15: 367-76.

9. Statistics South Africa. Mid-year population estimates, South Africa 2005 (accessed 2006, May 22). Available from: http://www.statssa.gov.za/publications/P0302/P03022005.pdf

10. THETA. Sector Skills Plan. (accessed 2006, June 29). Available from: http://www.theta.org.za/skills/index.asp?thepage=sector_skills.htm

11. Walker AR, Adam F, Walker BF. World pandemic of obesity: the situation in Southern African populations. Public Health 2001; 115: 368-72.

12. Walker AR, Walker BF, Segal I. Some puzzling situations in the onset, occurrence and future of coronary heart disease in developed and developing populations, particularly such in sub-Saharan Africa. $J R$ Soc Health 2004; $124:$ 40-6.

13. World Health Organisation. World Health Report 2002: Reducing risks, promoting healthy life (accessed 2006, May 23). Available from: http:// www.who.int/whr/2002/en/index.html

14. World Health Organisation. World Health Report 2003: Shaping the future (accessed 2006, May 23). Available from: http://www.who.int/whr/2003/en/ index.html

15. World Health Organisation. Global strategy on diet, physical activity and health (endorsed by the May 2004 World Health Assembly) (accessed 2006, May 23). Available from: http://www.who.int/dietphysicalactivity/en/

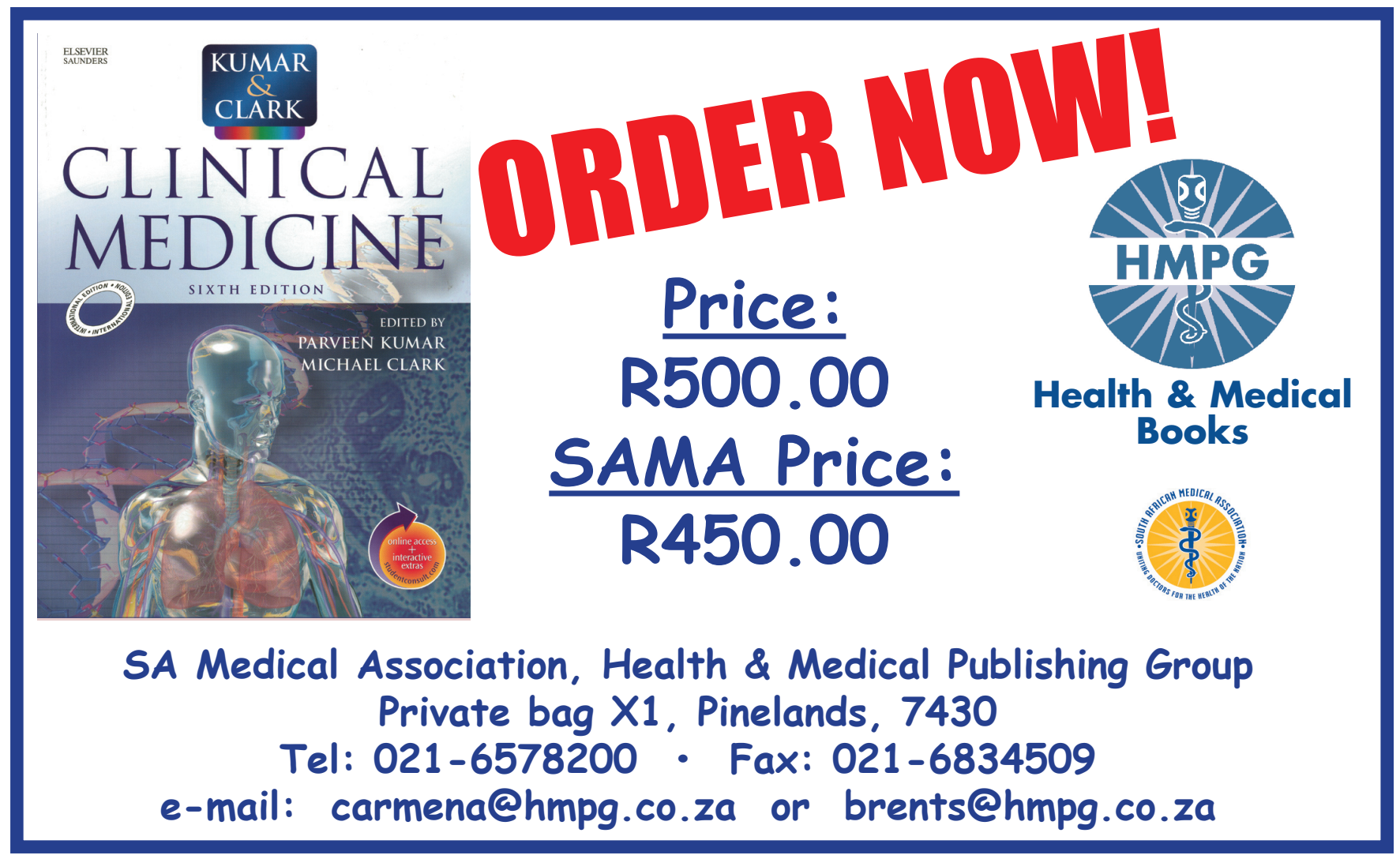

